Article

\title{
Electrochemical Synthesis of Nitro-Chitosan and Its Performance in Chromium Removal
}

\author{
Prashant K. Jha ${ }^{1, *}$, Gary P. Halada ${ }^{1}$ and Scott M. McLennan ${ }^{2}$
}

1 Department of Materials Science and Engineering, Stony Brook University, 314, Old Engineering Building, Stony Brook, NY 11794, USA; E-Mail: ghalada@ms.cc.stonybrook.edu

2 Department of Geosciences, Stony Brook University, 255 Earth and Space Sciences Building, Stony Brook University, Stony Brook, NY 11794, USA;

E-Mail: smclennan@notes.cc.sunysb.edu

* Author to whom correspondence should be addressed; E-Mail: pjha@ic.sunysb.edu; Tel.: +1-631-365-9344; Fax: +19735567955.

Received: 20 January 2013; in revised form: 10 July 2013 / Accepted: 12 July 2013 /

Published: 19 July 2013

\begin{abstract}
A synthesized polymeric form of chitosan, electrochemically precipitated and photochemically modified, has been found to have significant value in removal of toxic chromate oxyanions from solution. Fourier Transform Infra-Red (FTIR), Raman and X-ray photoelectron spectroscopy (XPS) indicated that a significant percentage of the amine functional groups were oxidized to nitro groups as a result of reactions with hydroxyl ions formed in the electrochemical process with additional oxidation occurring as a result of exposure to ultra-violet light. The adsorption capacity of the modified chitosan for chromate was investigated in a batch system by taking into account effects of initial concentration, $\mathrm{pH}$ of the solution and contact time. Nitro-chitosan showed greater adsorption capacity towards Cr (VI) than other forms of chitosan, with a maximum adsorption of $173 \mathrm{mg} / \mathrm{g}$. It was found that $\mathrm{pH} 3$ is the optimum for adsorption, a Langmuir model is the best fit for the adsorption isotherm, and the kinetics of reaction followed a pseudo second order function. Overall, our results indicate that electrochemical modification of chitosan is an effective method to enhance the reactivity of chitosan towards metals.
\end{abstract}

Keywords: chitosan; nitro-chitosan; electrochemical 


\section{Introduction}

Toxic metal contamination of soil and groundwater is a major environmental threat. Contamination from toxic heavy metals is present in as many as $63 \%$ of 1200 sites on the National Priority List of the U.S. Environmental Protection Agency (EPA) for treatment of contaminated groundwater. At 11\% of these sites chromium was found to be present making it one of the main toxic metal contaminants [1]. Chromium is used in industrial processes such as metal plating, leather tanning and pigment production resulting in release to groundwater [2]. In aerated aqueous solutions chromium is stable only as $\mathrm{Cr}(\mathrm{III})$ and $\mathrm{Cr}(\mathrm{VI})$ [3]. Although $\mathrm{Cr}$ (III) is essential for living beings in small amounts for its role in carbohydrate metabolism[4], it is toxic at higher concentrations. Also, in alkaline environments $\mathrm{Cr}$ (III) can oxidize to $\mathrm{Cr}(\mathrm{VI})$, which is toxic even at low concentrations, as it induces coetaneous allergies and is carcinogenic over long exposures [4,5]. Various methods developed for removal of toxic metals from groundwater include: isolation and containment, mechanical separation, pyrometallurgical separation, chemical treatment, permeable treatment walls, electrokinetics, biochemical processes, phytoremediation and soil flushing [1]. Chemical remediation using naturally occurring biodegradable biomass has generated a great deal of interest due to its low cost and high efficiency [6]. Some of the sorbents based on biomass are bark, seaweed, leaf mould and chitosan; detailed information on these and a comparison of their chemistry and performance can be found in work of S.E. Bailey et al. [7]. Chitosan is among the chief biomass-based remediation agents.

Chitosan is a linear, high molecular weight, crystalline polysaccharide consisting of $\beta-(1 \rightarrow 4)$ linked $N$-acetyl-D-glucosamine [8]. It is produced by alkaline $N$-deacetylation of chitin, the second most abundant natural polymer after cellulose [9]. Changing the acetamide group to amine increases the reactivity rendering chitosan a better chelation and adsorption agent than chitin [10]. The adsorption capacity of chitosan has been further enhanced using physical modifications including conditioning as gel beads and microcrystalline chitosan as well as chemical modifications such as cross-linking and insertion of new functional groups [11]. Chemical modification of chitosan utilizes the presence of primary amine and primary hydroxyl as well as secondary hydroxyl groups in the chitosan molecule, which makes it very amenable to further functionalization and modification. Chemical modifications of chitosan have been thoroughly reviewed by Mourya and Inamdar [12].

In the present work we report a novel electrochemical process followed by photochemical treatment for chitosan modification. The process results in formation of nitro groups through oxidization of a fraction of the amine groups of chitosan. The new biopolymer formed was characterized using spectroscopic techniques, and metal binding capacity was explored using chromium as chromate in aqueous solution. The adsorption capacity of the nitro-chitosan was compared with other forms of modified chitosan as reported in the literature.

\section{Results and Discussion}

\subsection{Electrodeposition}

Chitosan dissolves in acidic aqueous solution by addition of a proton to the $\mathrm{NH}_{2}$ group to form $\mathrm{NH}_{3}{ }^{+}$. The process is reversible and on increasing $\mathrm{pH}$ higher than 6.3, protonated chitosan deprotonates and precipitates. As reported previously by this group [13] as well as in work by Fernendes et al. [14], 
a localized zone of high $\mathrm{pH}$ is created near a cathode held at sufficiently negative potential in water, a method utilized in this process to electrochemically deprotonate protonated chitosan and form deposits on the steel substrate. Stainless steel is chosen as an electrode as it is inexpensive, easy to use, and does not corrode at cathodic potentials. The presence of an ultrathin passive layer on the steel enhances initial chitosan film formation and sorption, as was shown in our previous work.

During cathodic polarization, reduction of $\mathrm{H}^{+}$ions results in formation of $\mathrm{H}_{2}$ gas, as indicated by hydrogen bubble formation on the steel substrate. This removal of $\mathrm{H}^{+}$ions from solution creates a zone of high $\mathrm{pH}$ near the substrate where chitosan is deposited. The film thus formed is shown in the scanning electron microscopy (SEM) micrograph in Figure 1. The figure shows Chitosan was deposited in a multilayer structure. The first layer of chitosan is formed on the surface of hydrogen bubbles formed on the electrode (indicated in Figure 1 as the brightest area due to the most penetration of electrons from the substrate below) with diameter around $100 \mu \mathrm{m}$ (Figure 1). With the continuation of electrolysis and further accumulation of hydrogen, the bubbles collapse into each other to form larger bubbles of hydrogen $300-400 \mu \mathrm{m}$ in diameter, leaving the precipitated chitosan structure behind. An additional layer of chitosan is precipitated on top of the new bubbles formed (the areas with intermediate darkness in Figure 1). The process continues forming still larger bubbles with diameter $300 \mu \mathrm{m}$ to $1 \mathrm{~mm}$ forming the top layer of the precipitated chitosan film. The darkest areas (dark due to the blocking of electrons emitted from the substrate below by chitosan) in the figure are those with the maximum amount of chitosan which could have formed by transport of material along the bubble surface (hence making the top of the bubble progressively thinner until it breaks; the resulting fractures in this layer are clearly visible in the picture).

Figure 1. Scanning electron microscopy of electrochemically deposited chitosan on stainless steel at $-3.0 \mathrm{~V} v s$. $\mathrm{Ag} / \mathrm{AgCl}$ reference electrode.

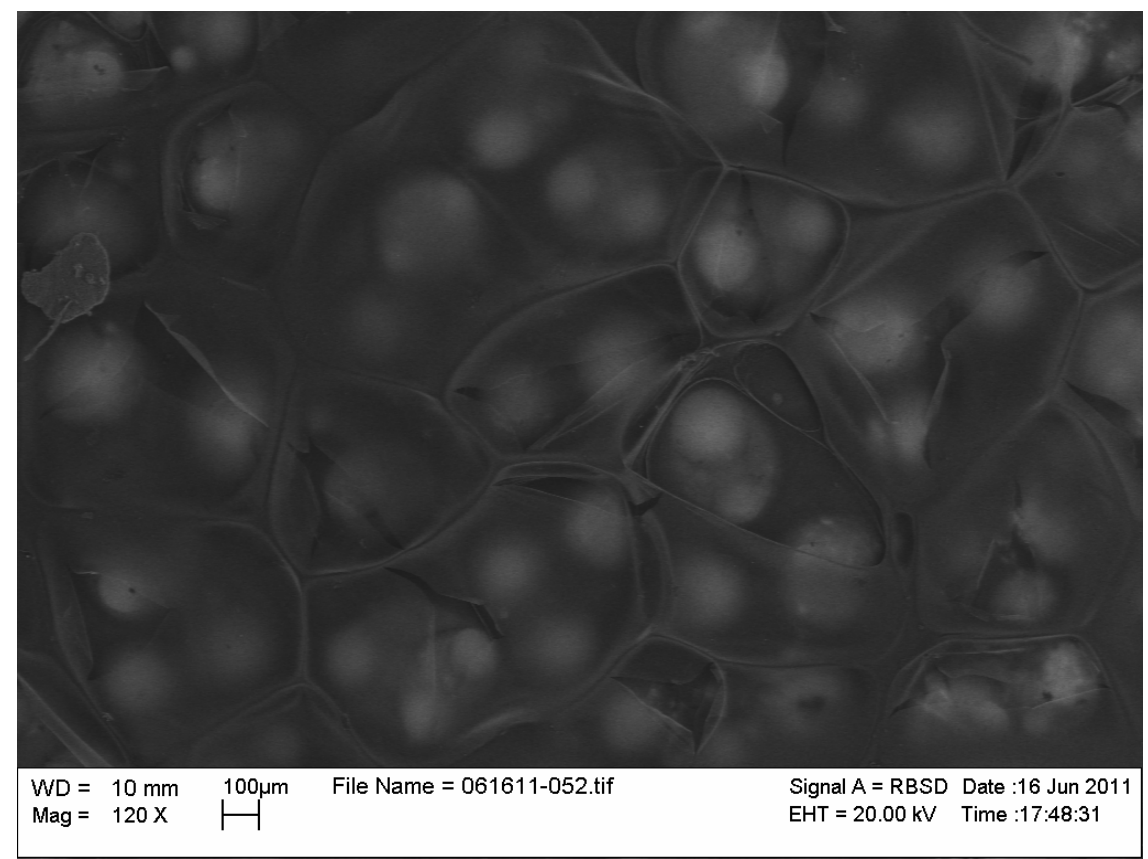




\subsection{Characterization}

The result of FTIR spectroscopy of the deposited material is summarized in Table 1. The peaks at $1663 \mathrm{~cm}^{-1}, 1203 \mathrm{~cm}^{-1}$ and $970 \mathrm{~cm}^{-1}$ indicate oxidation of some of the nitrogen in chitosan as a result of the electrochemical process. Raman spectra of the air-dried chitosan film as well as electrochemically modified chitosan are shown in Figure 2. The peak at $2920 \mathrm{~cm}^{-1}$ from the air-dried sample most likely results from a combination of asymmetric $\mathrm{C}-\mathrm{H}$ vibration from $\mathrm{CH}_{2} \mathrm{OH}$ and $\mathrm{C}-\mathrm{O}$ stretching vibration from the hydroxyl group. The broad peak at $1634 \mathrm{~cm}^{-1}$ is expected to result from a combination of amine $\mathrm{N}-\mathrm{H}$ deformation and aromatic $\mathrm{C}=\mathrm{C}$ stretching vibrations. The peak at $1465 \mathrm{~cm}^{-1}$ is expected to be from the $\mathrm{C}-\mathrm{H}$ scissor vibration while the peak at $1384 \mathrm{~cm}^{-1}$ is expected to be from the $\mathrm{CH}_{2}$ wagging. Peaks at $1325 \mathrm{~cm}^{-1}$ and $1188 \mathrm{~cm}^{-1}$ can be attributed to $\mathrm{C}-\mathrm{N}$ stretching from the amine group. The peak at $1256 \mathrm{~cm}^{-1}$ can be attributed to $\mathrm{OH}$ deformation vibration of the $\mathrm{CH}_{2} \mathrm{OH}$ group. The peaks at $1188 \mathrm{~cm}^{-1}$ and $820 \mathrm{~cm}^{-1}$ are expected to be from symmetrical and asymmetrical $\mathrm{C}-\mathrm{O}-\mathrm{C}$ stretching in cyclic ether while the peaks at $935 \mathrm{~cm}^{-1}$ and $468 \mathrm{~cm}^{-1}$ are expected from $\mathrm{C}-\mathrm{O}-\mathrm{C}$ bonds between monomer units. The peaks at $628 \mathrm{~cm}^{-1}$ and $560 \mathrm{~cm}^{-1}$ can be attributed to ring vibrations. Raman spectrum of electrochemically deposited material showed various new peaks: a peak at $3345 \mathrm{~cm}^{-1}$ from the $\mathrm{N}-\mathrm{H}$ stretching vibration in $\mathrm{C}=\mathrm{N}-\mathrm{H}$ groups while the peak at $1860 \mathrm{~cm}^{-1}$ is expected to be from the $\mathrm{C}=\mathrm{O}$ stretching vibration. The peak at $1589 \mathrm{~cm}^{-1}$ can be attributed to $\mathrm{N}-\mathrm{H}$ bending in the amine and the peak at $1525 \mathrm{~cm}^{-1}$ is consistent with the asymmetric $\mathrm{NO}_{2}$ stretching vibration. The peak at $901 \mathrm{~cm}^{-1}$ is consistent with the $\mathrm{C}-\mathrm{N}$ stretching vibration in nitro groups, and the new peak at $491 \mathrm{~cm}^{-1}$ is expected to be from the $\mathrm{NO}_{2}$ rocking vibration. Vibrational spectroscopy also indicates oxidation of a fraction of amine to imine and nitro groups as well as oxidation of some of the hydroxyl groups to aromatic ketone.

To confirm oxidation, XPS of the underside of a removed film layer (as described previously) was carried out. The resulting XPS spectrum of electrodeposited chitosan is shown in Figure 3. Two peaks are present for N1s; with charge correction, they correspond to binding energies of $398.6 \mathrm{eV}\left(\mathrm{NH}_{2}\right)$ and a large, broad peak at $407 \mathrm{eV}$. The peak at $407 \mathrm{eV}$ confirms the oxidation of nitrogen in chitosan, falling in the range of nitrate in cellulose nitrate $(408.1 \mathrm{eV})$ and $\mathrm{C}-\mathrm{NO}_{2}$ nitro compounds (406.3 eV) [15].

Table 1. Peak positions and assignments for the Fourier Transform Infrared spectrum of ECM-chitosan.

\begin{tabular}{cl}
\hline Peak $\left(\mathbf{c m}^{-\mathbf{1}}\right)$ & \multicolumn{1}{c}{ Assignment } \\
\hline 1663 & combination of amide $\mathrm{I} \mathrm{C=O}$ stretching, asymmetric $\mathrm{NO}_{2}$ stretching and $\mathrm{OH}$ deformation vibrations \\
1585 & NH bending frequency \\
1442 & $\mathrm{C}-\mathrm{C}$ stretching vibration \\
1380 & combination of $\mathrm{CH}_{3}$ deformation and $\mathrm{CO}$ stretching frequencies \\
1203 & combination of $\mathrm{NH}$ deformation and symmetric $\mathrm{NO}_{2}$ stretching vibrations \\
1154,1020 & symmetric and asymmetric stretching vibrations of C-O-C respectively \\
970 & amine oxide \\
805 & O-H deformation \\
\hline
\end{tabular}


Figure 2. Raman spectra of electrochemically modified chitosan (ECM) chitosan and dried chitosan solution at $\mathrm{pH} 2$.

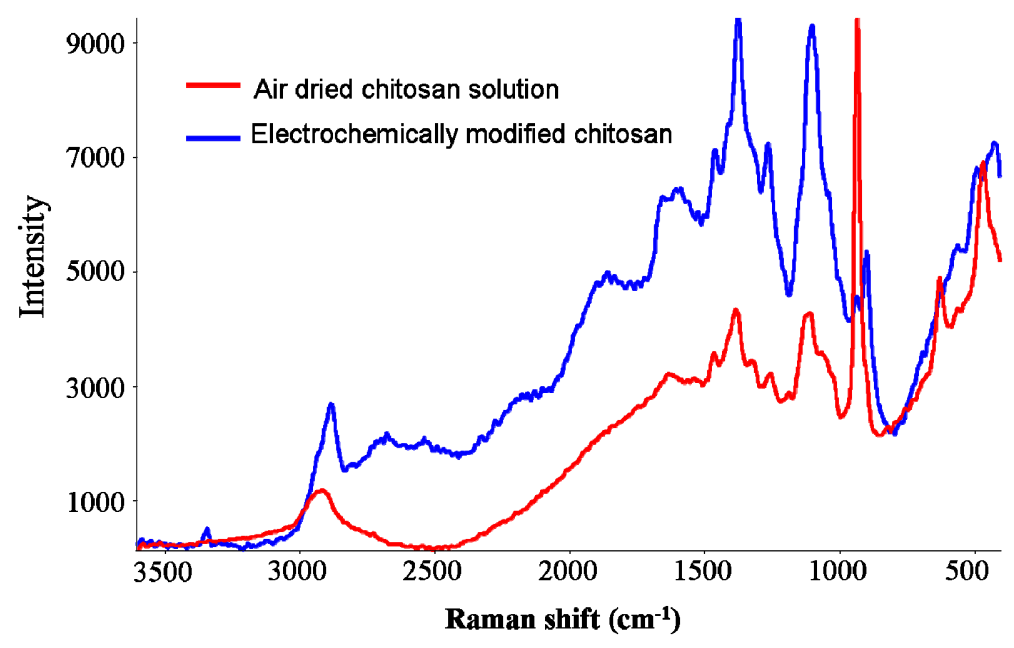

Figure 3. X-ray photoelectron spectroscopy (XPS) of electrodeposited chitosan. Peak 1: primarily amine $\left(-\mathrm{NH}_{2}\right)$, Peak 2 : similar to nitrate, possible nitronyl $(\mathrm{N}=\mathrm{O})$.

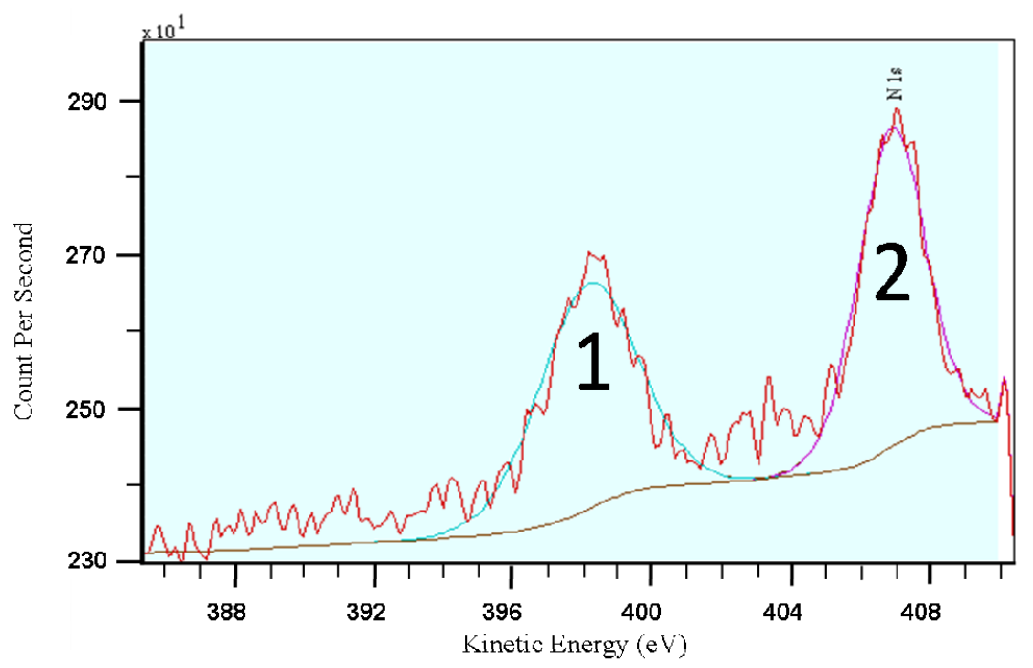

Hence, vibrational and X-ray spectroscopy provide clear evidence of oxidation of at least a portion of the amine groups in chitosan to nitro groups and some hydroxyl groups to aromatic ketone. The estimated structure of this novel molecule is shown in Figure 4. The oxidation can be due to reaction of amine and hydroxyl groups with $\mathrm{OH}^{-}$ions formed by electrolysis of entrapped water molecules in the hydrogel structure as shown in Equations below.

$$
\begin{gathered}
-\mathrm{NH}_{2}+\mathrm{OH}^{-} \rightarrow=\mathrm{NH}+\mathrm{H}_{2} \mathrm{O}+\mathrm{e}^{-} \\
=\mathrm{NH}+5 \mathrm{OH}^{-} \rightarrow=\mathrm{NO}_{2}+3 \mathrm{H}_{2} \mathrm{O}+5 \mathrm{e}^{-} \\
-\mathrm{OH}+\mathrm{OH}^{-} \rightarrow=\mathrm{O}+\mathrm{H}_{2} \mathrm{O}+\mathrm{e}^{-}
\end{gathered}
$$

Exposure of hydrogel to ultraviolet light was found to increase the intensity of the oxidized nitrogen peak in X-ray photoelectron spectroscopic spectrum (not shown) indicating oxidation of a higher fraction of amine. Enhanced oxidation of nitrogen by hydroxyl ion in the presence of UV light has also been observed by other researchers [16]. 
Figure 4. Structures of chitosan and nitro-chitosan synthesized by electrochemical deposition and photochemical oxidation.

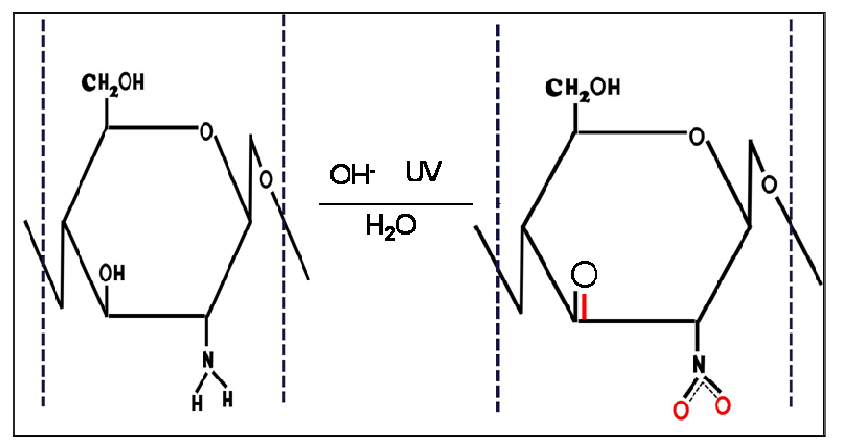

\subsection{Equilibrium Adsorption Isotherms}

The amount of metal adsorbed per unit mass of electrochemically modified (ECM)-chitosan, $Q_{\mathrm{e}}$, was calculated using formula:

$$
Q_{\mathrm{e}}=\left(C_{\mathrm{i}}-C_{\mathrm{e}}\right) V / M
$$

Where $C_{\mathrm{i}}$ is the initial concentration and $C_{\mathrm{e}}$ is the equilibrium concentration in $\mathrm{mg} / \mathrm{L}$ and $M$ is the dry mass of adsorbent in mg and $V$ is the volume in liters. The results of batch equilibrium adsorption are shown in Figure 5. The amount of chromium adsorbed by unit mass of ECM-chitosan increases with initial concentration of chromium till a plateau is achieved at $300 \mathrm{ppm}$, the result was similar to observations involving other forms of modified chitosan.using poly(2-acrylamido-2-methypropane sulfonic acid) and poly 3-methyl thiophene [17,18]. The adsorption capacity was found to be $174.4 \mathrm{mg}$ $\mathrm{Cr}(\mathrm{VI}) / \mathrm{g}$ of ECM-chitosan which is higher than values observed for modifications of chitosan by Verma et al. [19] and the references cited therein.

Figure 5. Isotherm for adsorption of $\mathrm{Cr}(\mathrm{VI})$ onto ECM-chitosan.

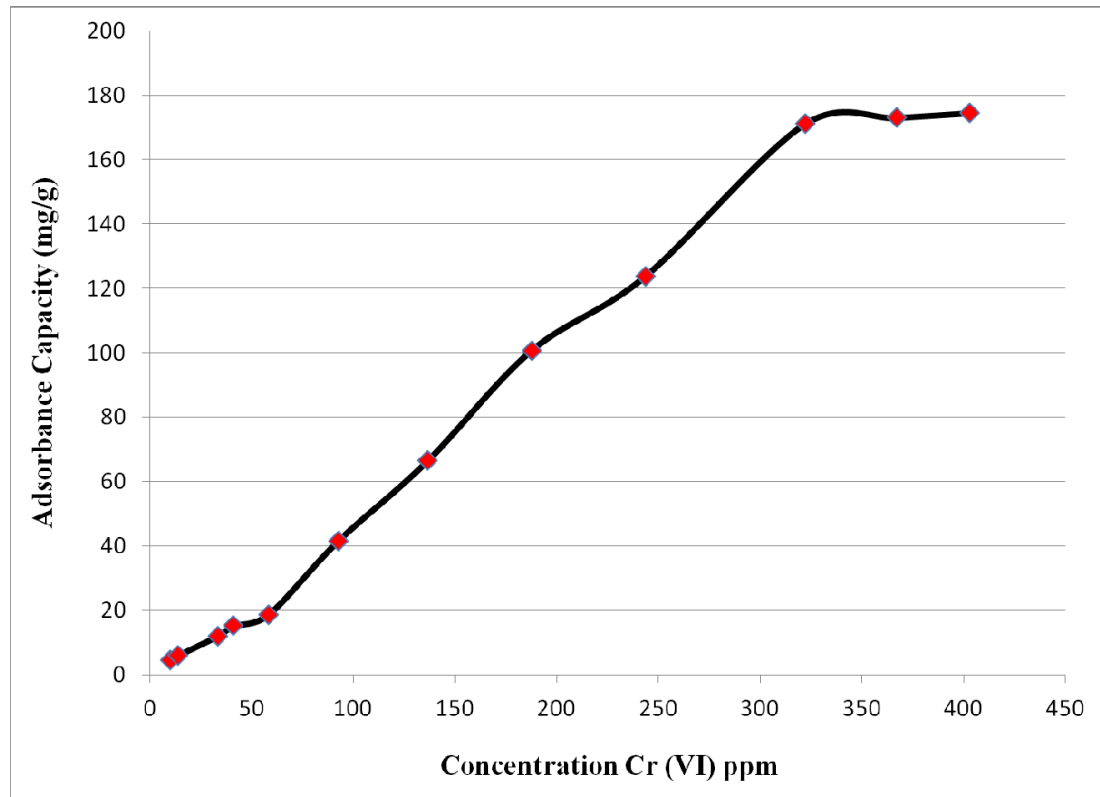


Equilibrium adsorption isotherms were used to investigate interactive behavior between the solution and adsorbent. A widely used Langmuir model which is representative of monolayer adsorption occurring on an energetically uniform surface without interactive molecules [20], was found to fit the process successfully (Figure 6). The Langmuir model (Equation 5) and its linear transformation (Equation 6) are given below.

$$
\begin{gathered}
Q_{\mathrm{e}}=Q_{\mathrm{m}} b C_{\mathrm{e}} /\left(1+b C_{\mathrm{e}}\right) \\
1 / Q_{\mathrm{e}}=1 / Q_{\mathrm{m}}+1 / b Q_{\mathrm{m}} C_{\mathrm{e}}
\end{gathered}
$$

Where $Q_{\mathrm{e}}$ is equilibrium adsorption capacity $(\mathrm{mg} / \mathrm{g}), C_{\mathrm{e}}$ is the solution concentration at equilibrium $(\mathrm{mg} / \mathrm{L}), Q_{\mathrm{m}}$ is the Langmuir constant representing maximum adsorption capacity $(\mathrm{mg} / \mathrm{g})$ and $b$ is the Langmuir constant related to energy of adsorption $(\mathrm{L} / \mathrm{mg})$. The calculated value of $Q_{\mathrm{m}}$ was $500 \mathrm{mg} / \mathrm{g}$ which is well above the experimentally observed value. The calculated value of $b$ was $0.001 \mathrm{~L} / \mathrm{mg}$, with a correlation coefficient $\left(R^{2}\right)$ of 0.9909 . A dimensionless separation factor $\left(R_{\mathrm{L}}\right)$ was used to determine the efficiency of adsorption obtained by equation $R_{\mathrm{L}}=1 /\left(1+b C_{0}\right)$ where $C_{0}$ is the initial concentration. The positive value calculated for $\mathrm{b}$ ensures an $R_{\mathrm{L}}$ value between 0 and 1 indicating the process of adsorption is feasible.

Figure 6. Langmuir plot for adsorption of Cr(VI) onto ECM-chitosan.

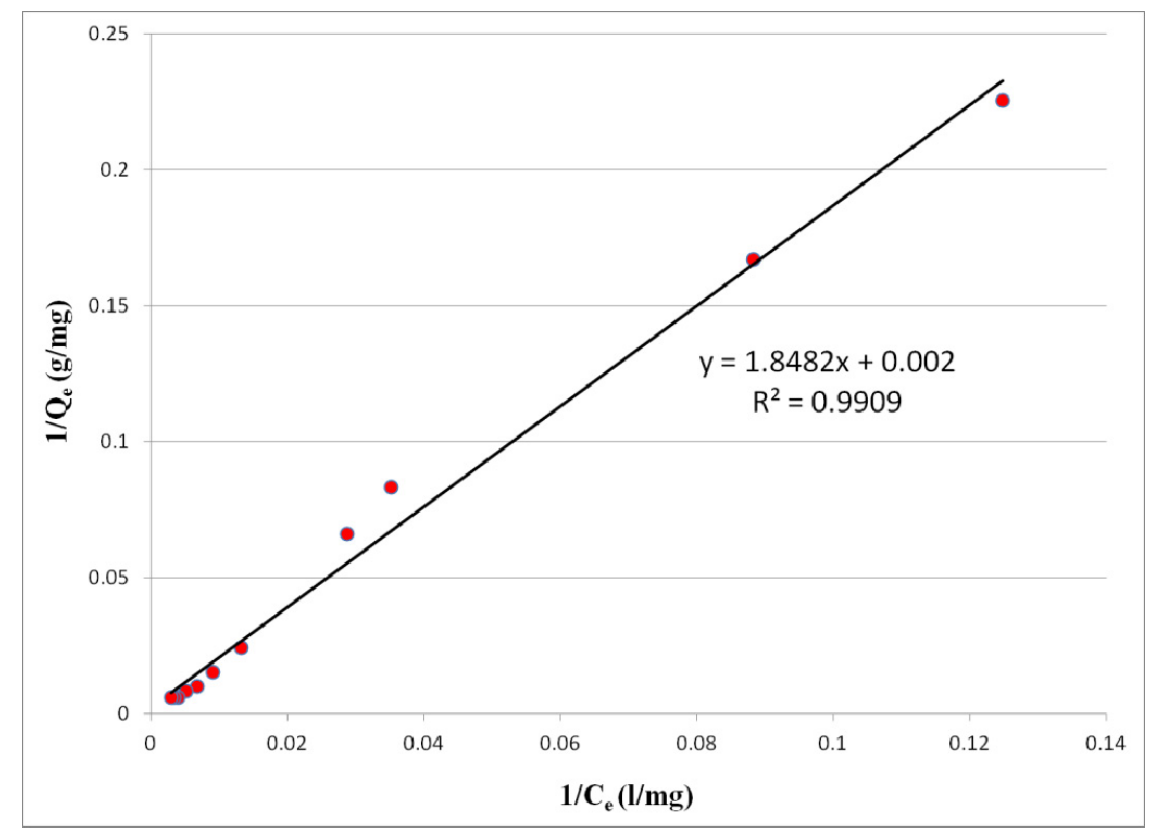

\subsection{Effect of $p H$ on Adsorption of Chromate}

The $\mathrm{pH}$ of the adsorption medium influences the physicochemical interactions between dissolved ions and adsorptive sites on the adsorbent [21]. The effect of $\mathrm{pH}$ on adsorption of $\mathrm{Cr}(\mathrm{VI})$ by electrochemically modified chitosan in the $\mathrm{pH}$ range of 1 to 8 is shown is Figure 7 . The maximum adsorption of $\mathrm{Cr}(\mathrm{VI})$ was observed for $\mathrm{pH} 3$ followed by a plateau region between $\mathrm{pH} 4$ and 7 , while the adsorption capacity of ECM-chitosan was found to collapse on reaching $\mathrm{pH}$ 8. Chromate exists as $\mathrm{HCrO}_{4}{ }^{-}$at acidic $\mathrm{pH}$, at intermediate $\mathrm{pH}\left(\mathrm{pH}\right.$ value 5-7) chromate exists as $\mathrm{HCrO}_{4}{ }^{-}$as well as $\mathrm{CrO}_{4}{ }^{2-}$, while at $\mathrm{pH}$ values higher than 7 , chromium exists as $\mathrm{CrO}_{4}{ }^{2-}$ [22]. 
The adsorption behavior at intermediate $\mathrm{pH}$ values can be due to several single or combined effects. Adsorption most likely occurs due to formation of a pendant structure with nitro and oxidized hydroxyl groups. At low $\mathrm{pH}$ the surface of the ECM-chitosan, just like pure chitosan, would be surrounded by oxidanium ions which would increase the attractive force between chromium(VI) and binding sites [23]. In very acidic solution ( $\mathrm{pH}$ value less than 3 ) the presence of excess oxidanium ion can lead to independent complexation with chromate thus rendering the attraction from ECM chitosan ineffective while formation of $\mathrm{CrO}_{4}{ }^{2-}$ as well as reduction in oxidanium ion can be the reason for declining adsorption with increasing $\mathrm{pH}$. Adsorption may also occur due to electrostatic attraction between any remaining positively charged amino groups and negatively charged chromate/dichromate ions in solution [24].

\subsection{Sorption Kinetics}

Chromium removal by ECM-chitosan as a function of contact time is shown in Figure 7. The reaction was rapid initially with 50\% metal uptake complete within the first 5 min after which it proceeded slowly and equilibrium was achieved in $3 \mathrm{~h}$. To further investigate the adsorption, mechanism and rate controlling step kinetic models were used. Pseudo first order, pseudo second order as well as inter particle diffusion models were used for analysis. The pseudo second order reaction (Equation 7) was found to fit the experimental data successfully (Figure 8).

$$
t / q_{\mathrm{t}}=1 / k q_{\mathrm{e}}^{2}+t / q_{\mathrm{e}}
$$

The value of $k$ was found to be $2.038 \mathrm{~g} / \mathrm{mg} \mathrm{h}$ with a linear correlation coefficient of 0.9987 indicating that the rate controlling step in chromium adsorption is chemisorption involving valence forces through the sharing or exchange of electrons between chromium and ECM-chitosan [25] in the concentration range tested.

Figure 7. Effect of $\mathrm{pH}$ (red) and contact time (blue) on chromium adsorption onto ECM-chitosan.

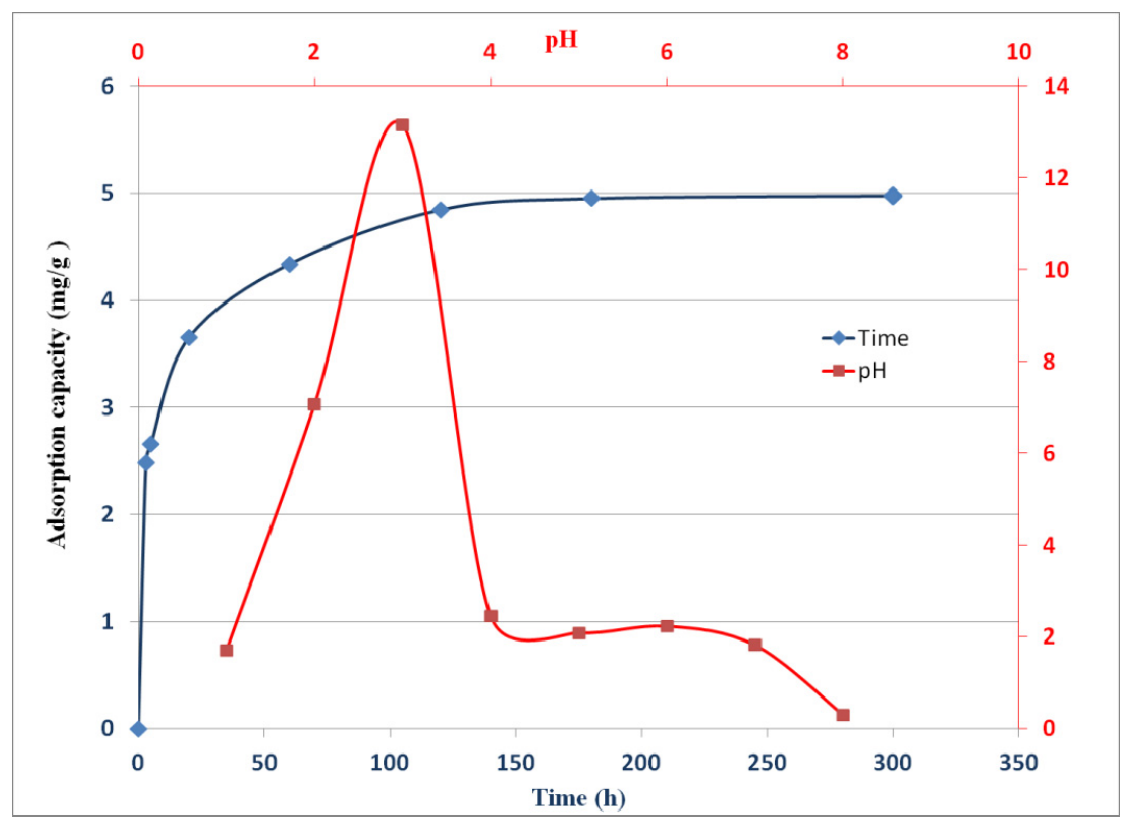


Figure 8. Curve fitting by pseudo second order reaction model on adsorption.

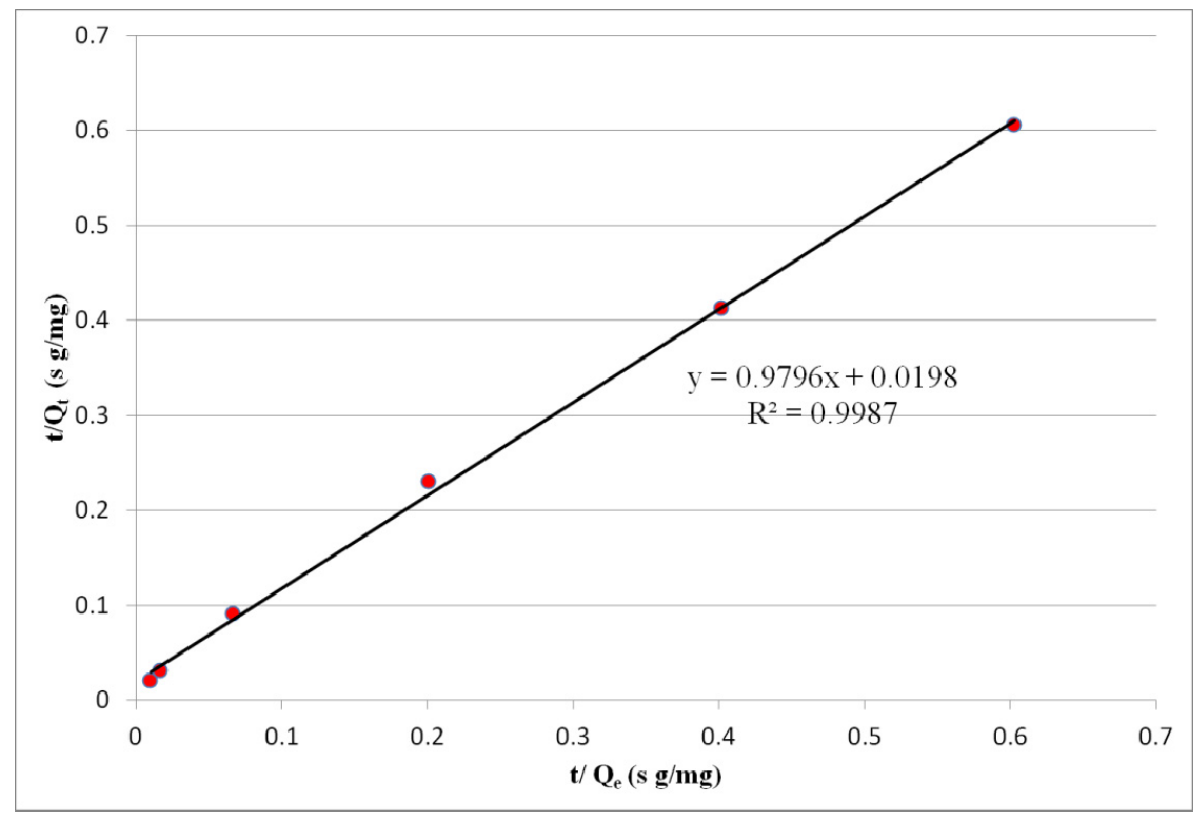

\section{Experimental Section}

\subsection{Electrodeposition of Chitosan}

The chitosan solution was made by mixing $1.5 \mathrm{~g}$ low molecular weight chitosan (Sigma Aldrich, Milwaukee, WI, USA, 75\%-85\% deacetylated) to $120 \mathrm{~mL}$ DI water under constant stirring. $\mathrm{HCl}(1 \mathrm{M})$ was then added drop wise until all the chitosan was dissolved, which occurred as the solution reached $\mathrm{pH}$ 2. For electrochemical deposition of chitosan, polished type 304 stainless steel (metal composition approx. $19 \% \mathrm{Cr}, 9 \% \mathrm{Ni}$, balance $\mathrm{Fe}$ ) was chosen as the working electrode. This process has been detailed by the authors in a previous publication [13]. Pt wire served as the counter electrode. A Gamry Reference 600 potentiostat was used to perform electrochemistry and Gamry Instrument Framework software was used for control and monitoring of voltage and current. Controlled potential coulometry at a voltage of $-3.0 \mathrm{~V}$ (versus $\mathrm{Ag} / \mathrm{AgCl}$ reference electrode) was applied for $5 \mathrm{~min}$. The resulting hydrogel was rinsed in DI water to remove any chitosan solution entrapped in the resulting hydrogel. The gel was then exposed to UV light $(20 \mathrm{~W}$ at $6 \mathrm{~cm})$ for $10 \mathrm{~min}$, following which it was then peeled from the electrode and left to dry further for $48 \mathrm{~h}$. A thin film may remain behind on the electrode surface, bound to the passive layer, as detailed in our previous work [13]. The film removed from the electrode was dried and then crushed mechanically to form powder for spectroscopic analysis and absorption experiments.

\subsection{FTIR}

Fourier Transform Infrared Spectroscopy (FTIR) spectra were obtained using a Nicolet 760 infrared spectrometer modified to collect data in both mid- and far infrared regions. Samples were ground to a fine powder. Spectra were collected using an MCT-A detector with data resolution set to $2 \mathrm{~cm}^{-1}$ and summed over 256 scans to improve the signal-to-noise ratio. A Gemini sampling accessory (Spectra-Tech, Madison, WI, USA) collected diffuse reflectance data from powder samples. The analysis chamber was 
purged continuously with doubly dried air to prevent the absorption of water vapor, and a globar-type IR source was used.

\subsection{Raman Spectroscopy}

A Nicolet Almega dispersive Raman spectrometer (Thermo Scientific, Madison, WI, USA) with a $785 \mathrm{~nm}$ laser source was used for analysis. Powdered samples were placed on quartz slides and Raman microspectroscopy in reflectance mode was used for data acquisition. Data was collected in the $3600-400 \mathrm{~cm}^{-1}$ range. An average of 10 scans with $5 \mathrm{~s}$ accumulation time for each exposure was collected and data was processed using OMNIC [26]. For comparison, chitosan solution at pH 3 was dried (without any applied potential) on stainless steel and similarly analyzed.

\subsection{XPS}

To detect speciation of nitrogen, X-ray photoelectron spectroscopic (XPS) studies were carried out. Sample preparation consisted of peeling off the deposited film from the stainless steel substrate after immersion in liquid nitrogen for one minute. The film was removed using a stainless steel razor and mounted on the XPS sample holder using indium foil. XPS measurements were performed using a custom-designed spectrometer that utilized a VG Scientific (Newburyport, MA, USA) CLAM2 hemispherical analyzer with lensing, controlled by a VGX900I data acquisition system. An Mg K $\alpha_{1,2}$ $(h v=1253.6 \mathrm{eV}) \mathrm{X}$-ray source operating at $20 \mathrm{kV}$ and $10 \mathrm{~mA}$ with a $20 \mathrm{eV}$ pass energy was used at a pressure of $1.33 \times 10^{-7} \mathrm{~Pa}$. Measurements were taken at a $90^{\circ}$ take-off angle with respect to the surface and charge correction was done by referencing to the $\mathrm{C} 1 \mathrm{~s}$ line of adventitious carbon $(284.6 \mathrm{eV})$.

\subsection{Absorption Experiments}

Stock solution (1000 ppm) of $\mathrm{Cr}(\mathrm{VI})$ was prepared by using $\mathrm{K}_{2} \mathrm{Cr}_{2} \mathrm{O}_{7}$ obtained from Sigma Aldrich, in deionized water $(>18 \mathrm{M} \Omega / \mathrm{cm})$ The stock solution was then diluted to give standard solutions of appropriate concentrations. Batch adsorption experiments were conducted in $250 \mathrm{~mL}$ conical flasks and equilibrated using a magnetic stirrer. This is similar to the method used in references [3,27] where $0.02 \mathrm{~g}$ of modified chitosan was added to $50 \mathrm{~mL}$ of standard solution and equilibrated for $30 \mathrm{~min}$. Supernatant solution was then filtered and analyzed. For equilibrium time determination, $0.5 \mathrm{~g}$ of modified chitosan was mixed in $1 \mathrm{~L}$ of $26 \mathrm{ppm} \mathrm{Cr}$ (VI) solution under constant stirring. Samples of two milliliters of solution were removed at predetermined times, filtered and analyzed. To determine the effect of $\mathrm{pH}$ on adsorption, the $\mathrm{pH}$ of the $26 \mathrm{ppm} \mathrm{Cr}$ solution was controlled by introducing a small amount of $1 \mathrm{M} \mathrm{HCl}$ and $1 \mathrm{M} \mathrm{NaOH}$ solutions as required, while the remaining parameters were kept the same as for the batch experiments. Chromium concentrations were measured using DCP-AES.

\subsection{DCP-AES}

Elemental analyses were carried out with an Applied Research Laboratories Spectraspan (Valencia, CA, USA) VB Direct Current Argon Plasma Atomic Emission Spectrometer (DCP-AES,). This system uses a Czerny-Turner spectrometer with an Echelle grating and $30^{\circ}$ prism for order separation. At $400 \mathrm{~nm}$ reciprocal linear dispersion is $0.122 \mathrm{~nm} / \mathrm{mm}$ and for a $25 \mu \mathrm{m}$ entrance slit spectral band pass is 
$0.0030 \mathrm{~nm}$. Analyses were performed in single element mode, using standard settings and a solution flow rate of $0.5 \mathrm{~mL} / \mathrm{min}$. Emission lines used for analyses were Cr $425-435 \mathrm{~nm}$.

Standards used for calibration for $\mathrm{Cr}$ analyses were prepared from commercially available single element 1000 ppm emission spectroscopy stock solution standards prepared in 1\%-2\% nitric acid. Net counts were calibrated using a "two-point" calibration system involving a blank and a high standard that was prepared to be slightly more concentrated than the highest concentration sample, thus bracketing the concentration range of the samples. Three to four additional standards, spanning the full concentration range of the samples, were also prepared and run as "unknowns" to confirm linear calibration curves and to monitor reproducibility. Samples were run in duplicate.

\section{Conclusions}

Electrochemical deposition of chitosan is an effective method to form chitosan hydrogel coating on conducting surfaces. The coating formed by electrochemical deposition becomes chemically modified with some of the amine groups changing to nitro groups. The modification is further enhanced by exposing the hydrogel to ultra-violet light. Modified chitosan containing nitro groups can have tremendous applications in various fields from remediation to drug delivery because of its higher affinity towards negatively charged metallic ions than chitosan.

\section{Acknowledgments}

This work was partially supported by a Stony Brook University/Brookhaven National Laboratory SEED grant.

\section{Conflict of Interest}

The authors declare no conflict of interest.

\section{References}

1. Mulligen, C.N.; Yong, R.N.; Gibbs, B.F. Remediation technologies for metal-contaminated soils and groundwater: An evaluation. Eng. Geol. 2001, 60, 193-207.

2. Wilkin, R.T.; Su, C.; Ford, R.G.; Paul, C.J. Chromium-removal process during groundwater remediation by a zerovalent iron permeable reactive barrier. Environ. Sci. Technol. 2005, 39, 4599-4605.

3. Wan Ngah, W.S.; Kumari, A.; Fatinathan, S.; Ng, P.W. Adsorption of chromium from aqueous solution using chitosan beads. Adsorption 2006, 12, 249-257.

4. Baroni, P.; Vieira, R.S.; Meneghetti, E.; da Silva, M.G.C.; Beppu, M.M. Evaluation of batch adsorption of chromium ions on natural and crosslinked chitosan membranes. J. Hazard. Mater. 2008, 152, 1155-1163.

5. Loyaux-lawniczak, S.; Lecomte, P. Chromium in a polluted groundwater: Redox process and immobilization in soils. Environ. Sci. Technol. 2001, 35, 1350-1357.

6. Wang, J.; Peng, R.; Bao, Z.; Yang, J.; Chen, S.; Liu, Q. Quick Removal of Chromium (VI) Ions from Aqueous Solution by Chitosan and Ferrous Ions. In Proceedings of IEEE 4th International 
Conference on Bioinformatics and Biomedical Engineering (ICBBE), Chengdu, China, 18-20 June 2010; pp. 1-4.

7. Bailey, S.E.; Olin, T.J.; Bricka, R.M.; Adrian, D.D. A review of potentially low-cost sorbents for heavy metals. Water Res. 1999, 33, 2469-2479.

8. Modrzejewska, Z.; Maniukiewicz, W.; Wojtasz-pajak, A. Determination of Hydrogel chitosan membrane structure. Polish Chitin Soc. Monogr. XI 2006, 113-121.

9. Nunthanid, J.; Puttipipatkhanachorn, S.; Yamamoto, K.; Peck, G.E. Physical properties and molecular behavior of chitosan films. Drug Dev. Ind. Pharm. 2001, 27, 143-157.

10. Guibal, E. Interactions of metal ions with chitosan-based sorbents: A review. Separ. Purif. Tech. 2004, 38, 43-74.

11. Rojas, G.; Silva, J.; Flores, J.A.; Rodriguez, A.; Ly, M.; Maldonado, H. Adsorption of chromium onto cross-linked chitosan. Separ. Purif. Tech. 2005, 44, 31-36.

12. Mourya, V.K.; Inamdar, N.N. Chitosan-modifications and applications: Opportunities galore. React. Funct. Polym. 2008, 68, 1013-1051.

13. Halada, G.P.; Jha, P.; Nelson, K.; Zhao, W.; Korach, C.S.; Neiman, A.; Lee, S.J.; Mintzer, E. Formation and characterization of chitosan-based coatings on stainless steel. In Biomaterials; Kulshrestha, A.S., Mahapatro, A., Henderson, L.A., Eds.; ACS symposium series; American Chemical Society: Washington DC, USA, 2010; pp. 159-171.

14. Fernendes, R.; Wu, L.Q.; Chen, T.; Yi, H.; Rubloff, G.W.; Ghodssi, R.; Bentley, W.E.; Payne, G.F. Electrochemically induced deposition of a polysaccharide hydrogel onto a patterned surface. Langmuir 2003, 19, 4058-4062.

15. Beard, B.C. Cellulose nitrate as a binding energy reference in N(1s) XPS studies of nitrogen-containing organic molecules. Appl. Surf. Sci. 1990, 45, 221-227.

16. Berger, P.; Vel Leitner, N.K.; Dore, M.; Legube, B. Ozone and hydroxyl radicals induced oxidation of glycine. Water Res. 1999, 33, 433-441.

17. Gad, Y.H. Preparation and characterization of poly(2-acrylamido-2-methypropane sulfonic acid)/chitosan hydrogel using gamma irradiation and its application in wastewater treatment. Radiat. Phys. Chem. 2008, 77, 1101-1107.

18. Hena, S. Removal of chromium hexavalent ion from aqueous solutions using biopolymer chitosan coated with poly 3-methyl thiophene polymer. J. Hazard. Mater. 2010, 181, 474-479.

19. Verma, B.M.; Krishnaiah, A.; Talbott, J.L.; Edgar, S.D. Removal of Hexavalent Chromium from wastewater using a new composite chitosan biosorbent. Environ. Sci. Technol. 2003, 37, 4449-4456.

20. Aydin, Y.A.; Aksoy, N.D. Adsorption of chromium on Chitosan: Optimization, kinetics and thermodynamics. Chem. Eng. J. 2009, 151, 188-194.

21. Aksu, Z.; Gonen, F.; Demircan, Z. Biosorption of chromium(VI) ions by Mowital B3OH resin immobilized activated sludge in a packed bed: comparison with granular activated carbon. Process Biochem. 2002, 38, 175-186.

22. Qin, C.; Du, Y.; Zhang, Z.; Liu, Y.; Xiao, L.; Shi, X. Adsorption of Chromium (VI) on a novel quaternized chitosan resin. J. Appl. Polym. Sci. 2003, 90, 505-510.

23. Baran, A.; Bicak, E.; Baysal, S.H.; Onal, S. Comparative studies on the adsorption of Cr(VI) ions on to various sorbents. Bioresour. Technol. 2006, 98, 661-665. 
24. Sabharwal, S.; Ramnani, S.P. Adsorption behavior of $\mathrm{Cr}(\mathrm{VI})$ onto radiation crosslinked chitosan and its possible application for the treatment of wastewater containing $\mathrm{Cr}(\mathrm{VI})$. React. Funct. Polym. 2006, 66, 902-909.

25. Hu, X.J.; Wang, J.S.; Liu, Y.G.; Li, X.; Zeng, G.; Bao, Z.; Zeng, X.; Chen, A.; Long, F. Adsorption of chromium (VI) by ethylenediamine-modified cross-linked magnetic chitosan resin: Isotherms, Kinetics and thermodynamics. J. Hazard. Mater. 2011, 185, 306-314.

26. OMNIC for Nicolet Almega, version 7.3 service pack 1; Thermo Electron Corporation: Waltham, MA, USA, 2006.

27. Sun, X.; Peng, B.; Ji, Y.; Chen, J.; Li, D. Chitosan(chitin)/cellulose composite biosorbents prepared using ionic liquid for heavy metal ions adsorption. AIChE J. 2009, 55, 2062-2069.

(C) 2013 by the authors; licensee MDPI, Basel, Switzerland. This article is an open access article distributed under the terms and conditions of the Creative Commons Attribution license (http://creativecommons.org/licenses/by/3.0/). 